\title{
A UTOPIA ANARQUISTA EM PORTO ALEGRE NOS ANOS DE 1906 E 1907 \\ Os anarquistas porto-alegrenses do periódico A Luta e a sua tentativa de mudar o rumo local da História
}

Evangelia Aravanis ${ }^{1}$

"Acima da sociedade real, construíase, pouco a pouco, uma sociedade imaginária (...). Perdeu-se o interesse pelo que era para pensar no que podia ser e, enfim, viveu-se pelo espírito nessa cidade ideal que os escritores haviam construído."

Alexis de Tocqueville

$\mathrm{O}$ anarquismo, enquanto uma das expressões do socialismo, se fez portador de projetos de sociedade que tinham como centro a proposta do fim das relaçóes de poder - entendido aqui como autoridade existentes nas sociedades.

$\mathrm{O}$ presente artigo objetiva expor e analisar alguns fragmentos do projeto de sociedade elaborado pelos anarquistas porto-alegrenses

1 Mestranda junto ao Programa de Pós-Gradução em História da UFRGS. Professora do Curso de História da ULBRA. Este artigo resume alguns pontos tematizados em minha dissertação de mestrado que se encontra em fase de conclusāo. 
do periódico A Luta nos anos de 1906 e 1907, buscando inventariar se o projeto social proposto por estes anarquistas realmente se apresenta, tal como seria no anarquismo, enquanto uma alternativa e uma forma de resistência aos poderes que, neste momento, na sociedade local, estão constituídos e/ou se consolidando.

Nesta exposição do projeto de sociedade configurado pelo grupo do A Luta destacar-se-á também o conteúdo utópico presente no mesmo, visto este ser um importante elemento para entender a radicalidade dos anseios de transformação social do grupo em questão, já que, pode-se dizer, o anarquismo constitui-se numa das mais puras formas de manifestação utópica.

\section{As relações entre o anarquismo e o fenômeno utópico}

Antes de iniciar a pretendida análise do discurso do periódico $A$ Luta, nos anos em questão, faz-se necessário apresentar aqui algumas definições e associações. Como se compreende o anarquismo? O que é utopia - o fenômeno utópico - e qual a sua relação com esta doutrina?

Certamente esboçar, mesmo que sucintamente, uma definição do anarquismo não é uma das tarefas mais simples, visto a sua constante variação no tempo e no espaço. No entanto, é exatamente nesta característica, que o torna de difícil definição, que se pode encontrar uma conceitualização satisfatória desta doutrina.

$\mathrm{O}$ anarquismo é uma doutrina que fundamenta todas as suas manifestações a partir de uma determinada noção de liberdade surgida na modernidade. Ela é a expressão mais pura desta concepção de liberdade moderna e por isso pode-se vê-lo tomando esta concepção como noção norteadora de todas as suas reflexões e ações ${ }^{2}$.

Esta concepção é a idéia de que a liberdade deve ser social, de que as liberdades individuais não devem estar em oposição entre si criando, assim, proeminências de liberdades, mas somando-se até

2 Esta idéia, bem como a conceitualização desta - que logo aparecerá no corpo do texto -, encontra-se em Maitron, 1975, tomo I:13-41 e em alguns intelectuais acadêmicos anarquistas: Bertollo, 1982:118-120 e Berti, 1981:4-14. Estes últimos, no entanto, nāo sāo aqui considerados como uma referência teórica, mas como uma forma de compreender como anarquistas pensam e conceituam o anarquismo. 
comporem a liberdade coletiva. Objetivamente, todas as ações e pensamentos desenvolvidos por esta doutrina devem ter como base o pressuposto da intocabilidade da liberdade alheia. Um projeto de sociedade anarquista, por exemplo, deve estabelecer um igual acesso de todos aos meios de produção, pois acessos diferenciados levariam a uma desigualdade de exercícios de liberdades. Ações ou valores culturais, para citar mais um exemplo, não poderiam ser impositivos, pois, assim, haveria hierarquizações de papéis, gêneros, etc. e, novamente, uma desigualdade de liberdades.

A variação da doutrina anarquista no tempo e no espaço, nada mais é, como se pode depreender do acima exposto, do que reflexo de sua noção fundante, já que o igualitarismo que se quer ver realizado em todas as instâncias do social ali se expressa no exercício da noção de que todos são igualmente livres para pensarem e agirem sobre os diferentes pontos sobre os quais o anarquismo se debruça - os métodos de luta, a forma de organização da futura sociedade etc. ${ }^{3}$. É por isso que afirmei ser esta variação temporal/espacial uma importante referência para uma definição da doutrina anárquica, visto o anarquismo ser, por princípio, devido a sua noção fundante de liberdade, uma doutrina aberta.

Com relação às utopias, o que se pode primeiramente dizer é que elas são a mais pura manifestação do desejo. Este desejo, que surge nos homens frente às realidades sociais consideradas por eles como inóspitas, faz com que estes as neguem e elaborem em relação a elas uma evasão - uma compensação frente a este "mal" -, que se estrutura através de um imaginário: o imaginário utópico (cf. Müller, 1989:34/35).

Este imaginário, em função do desejo que o impulsiona, é formado por idéias-imagens de uma sociedade outra, no sentido essencial de ser a negação desta, estando, assim, em oposição total à ordem social existente, a suas instituições, ritos, símbolos dominantes; a seus sistemas de valores, normas, interdições; a suas hierarquias, relações de dominação e propriedade, etc. ${ }^{4}$

3 Algumas definiçōes do anarquismo têm agrupado estas variaçōes da doutrina, realizando, a partir delas, uma ordenação do anarquismo em diferentes grupos ou correntes. Ver neste sentido: Woodcock, 1990 e Horowitz, 1982.

4 Esta afirmativa foi elaborada tendo por base as definiçōes de Baczko e Voisin sobre a alteridade utópica. É importante colocar aqui, no entanto, em nome de uma precisão conceitual, que Baczko, apesar de definir como representaçōes 
Esta sociedade outra imaginada também se coloca sempre de forma imediata em oposição ao presente (Baczko, 1978:51-55). Podese dizer, nesta perspectiva, que o desejo que informa as utopias estrutura-se em um querer que precisa logo se satisfazer nem que seja, tão somente, através do imaginário por ele constituído. Neste sentido é que se torna possível falar que as utopias são a mais pura manifestação humana de negação radical do presente, visto elas serem a consubstancialização do desejo dos homens de não quererem mais nem um minuto destas sociedades existentes. O fim delas, assim, deve se dar aqui e agora, já!

Quando esta sociedade outra imaginada tem ainda como característica ser nova - nem sempre é assim -, observa-se que os homens não estão só negando, em suas representações, toda a sociedade vigente, mas desejando, ao nível do imaginário, uma sociedade inusitada na história. Isso porque eles estão operando, em suas representações, não só uma negação do presente, mas, ao propor o novo, interditando uma re-apresentação do passado, bem como, uma continuidade deste presente.

O anarquismo, enquanto uma das expressões do socialismo, constitui-se numa das mais puras formas de manifestação utópica, e isto porque se coloca, e de forma imediata, em total oposição às sociedades baseadas na dominação (na autoridade) que lhe foram coetâneas ao longo do tempo ${ }^{5}$. Isso se deve ao fato do anarquismo, ao pretender a liberdade coletiva, passar a negar de forma total e imediata

utópicas aquelas que apontam para uma sociedade outra (Baczko, 1978:30), estas foram sempre adjetivadas, no decorrer de seu trabalho, como "novas", diferentemente de Voisin. Este último faz uma clara distinção entre as alteridades que se fundam no novo ("progressivas") e aquelas que se fundam no velho ("retrogressivas") (Voisin, 1990:39/40).

5 Estou considerando autoridade qualquer prática que signifique a tentativa de hierarquização ou hierarquização efetiva das liberdades no social, i. é., tal como é concebida pelo ideário anárquico. Via de regra, são consideradas autoridade somente as hierarquias que se estabilizaram e se institucionalizaram nas sociedades e demandaram, em funçâo disso, uma obediência incondicional (Stoppino, in: Bobbio [et. al.], 1993:88-92). Como se pode ver, a definição anarquista de autoridade reflete a própria intenção anárquica de solapar as bases constituidoras da autoridade, pois ao questionar a autoridade a partir do surgimento de qualquer tentativa de hierarquização das liberdades, os anarquistas demonstram a sua intenção de inviabilizá-la - a sua estabilização e institucionalização - nas sociedades. 
este presente, pois, caso contrário, fragmentos desta sociedade continuariam existindo e também se abriria mão, mesmo que momentaneamente, da liberdade coletiva. $\mathrm{O}$ anarquismo, nesta sua negação do presente, se coloca, como se pode observar, totalmente à margem deste presente, pois propõe a construção de uma sociedade outra, diferente da existente, a sua sociedade. É importante deixar claro, no entanto, que isto enquanto possibilidade, quando os anarquistas permanecem apegados à noção de liberdade fundante de seu ideário, visto não terem sido poucas as vezes que eles reproduziram as sociedades de seu tempo.

\section{Os anarquistas porto-alegrenses do periódico A Luta: a sua negação do presente e o seu desejo de uma sociedade outra}

Os anarquistas do A Luta, mesmo tendo sofrido forte influência do "sindicalismo revolucionário" que vinha emergindo desde a virada do século XX, colocaram-se, em vários momentos, muito próximos dos moldes anárquicos "clássicos" quanto à crítica ao poder existente nas sociedades e quanto à construção de projetos sociais alternativos as sociedades baseadas na dominação ${ }^{6}$

A influência desta doutrina emergente - o "sindicalismo revolucionário" - fazia com que os anarquistas do A Luta compactuassem momentaneamente com os poderes existentes na esfera econômica da

6 Como se pode ver, o que a historiografia, muitas vezes, toma por anarcosindicalismo está sendo aqui denominado de "sindicalismo revolucionário". Considero mais apropriado este termo visto esta última doutrina não poder ser classificada como uma das correntes do anarquismo, diferente de como faz esta historiografia quando se refere ao anarco-sindicalismo. A razão disso deve-se por esta doutrina não fundamentar-se, tal qual o anarquismo, na concepção de que a liberdade deve ser social. Baseio-me, para afirmar isso, em Maitron, 1975; Tomo I: 265-330. É preciso, no entanto, alertar que, neste momento, o "sindicalismo revolucionário" encontrava-se em estado latente e ainda indissociado do anarquismo, vindo somente, em agosto de 1907, após o Congresso anarquista de Amsterdã, a tornar-se um corpo autônomo em relação ao anarquismo. É por isso que também considero aqui o grupo do $A$ Luta ainda como "anarquista", apesar da influência desta doutrina emergente que, é importante dizer, nẩo era sentida por aqui, mesmo após o Congresso anarquista de Amsterdā, até pelo menos final de 1907 , como algo dissociado do anarquismo. 
sociedade porto-alegrense. Isso porque esta influência os fazia crer que através de conseqüentes movimentos - greves, paralisações, etc. visando conquistas econômicas, se acentuaria a luta de classes, e os trabalhadores ao tomarem consciência da exploração sofrida, passariam, automaticamente, a desejar uma sociedade outra, diferente da existente (Maitron, 1975; Tomo I: 322/323). Nestas situações, configurava-se no discurso destes anarquistas uma proposta de mudança que adquiria uma forma tencional entre reformar a ordem econômica existente e o que seria a sua conseqüência: o fim da mesma.

Quando do movimento grevista de 1906 ocorrido na cidade 7 , não foram raros os discursos que evidenciavam esta tensão. Pretendiase, ao fazer parte desse movimento, "redu[zir] um pouco os lucros dos detentores do capital, conquis[tando] para os que trabalham um relativo bem estar"s. Tudo isto para que os trabalhadores pudessem ter mais tempo para "estudar (o anarquismo) e pensar (sobre a exploração do operariado)", visto que, quando isso acontecesse, "esta[ria] perdida a burguesia"?

Denunciavam, ainda, em outras situações, mesmo que aceitandoas temporariamente, formas variadas de poder no âmbito econômico que iam desde aquelas resultantes da apropriação dos meios de produção por determinados grupos ${ }^{10}$, a "exploração" "criminosa", apesar de que entendida como necessária à subsistência da família operária, do trabalho das "crianças" nas oficinas ${ }^{11}$, devido à baixa remuneração do operário adulto.

Propunham, em oposição a esta esfera da sociedade portoalegrense da época, uma outra onde os meios de produção fossem "propriedade social"12. Criticavam enfaticamente, nestas situaçôes, o

7 Como bem se sabe, este movimento constituiu o primeiro grande enfrentamento ocorrido entre o capital e o trabalho em Porto Alegre.

8 A Luta, 13/9/1906, número I, p. 2.

9 Polydoro Santos, "As oito horas". In: A Luta, 28/10/1906, número 4, p. 3.

10 Ver, por exemplo, "Ecos das Oficinas". In: A Luta, 15/12/1906, número 7, p. 2 e A Luta, 10/10/1906, número 3, p. 2.

11 A Luta, 3/9/1907, número 22, p. 2. Desde o início do século XX, com a introdução do maquinário nas oficinas, a mão de obra infantil já vinha sendo empregada em Porto Alegre. O operariado, apesar da baixa remuneração do trabalho infantil, vinha buscando através deste expediente aumentar a renda familiar (cf. Pesavento, 1988: 37,59).

12 "Duas Palavras". In: A Luta, 10/10/1906, número 3, p. 1. 
processo de apropriação que já ocorria há alguns anos dos instrumentos de trabalho dos operários, por parte do capital ligado às oficinas (cf. Pesavento, 1994:36/37) ${ }^{13}$. Acreditavam que através de uma nova organização econômica desta sociedade, ninguém estaria coagido a trabalhar para outro visando sobreviver e a infância poderia, então, ficar livre desta forma de subjugação e "instruir-se"14.

A forma de produção e distribuição da riqueza nesta sociedade deveria ainda, para que esta não se desestruturasse, obedecer ao seguinte princípio: "De cada um conforme suas forças, e a cada um conforme as suas necessidades"15. Esta seria a forma mais igualitária possível de se conceber a produção e distribuição da riqueza, pois não seria justo que quem tivesse menos energia trabalhasse da mesma forma que um outro com mais fôlego, ou recebesse, em função desta limitação biológica, menos do que compreendesse como necessário ${ }^{16}$. Poderia perguntar-se aqui se tal não-correlação entre a produção e a distribuição da riqueza não seria uma forma destes anarquistas discriminarem as liberdades, visto que poderia ocorrer que indivíduos com mais força acabassem sendo obrigados a sustentar as necessidades daqueles com menos energia. Acredito que, muito provavelmente, esta idéia não se fazia presente na lógica destes anarquistas do A Luta, pois eles forneceram indícios de que acreditavam em uma natureza social harmônica, onde a abundância - que se manifestaria em todas as esferas desta sociedade (na natureza, na produção de bens, etc.) - seria um fator regulador natural que inibiria um possível desequilíbrio, como este ${ }^{17}$.

13 A Luta, $1 / 7 / 1907$, número 20 , p. 2 . O termo operário aqui utilizado se refere a tipos de sujeitos trabalhadores que extrapolam aqueles que comumente se tomam por operários. Concebo por operários aqueles grupos que vivem de seu trabalho, via de regra assalariado, e que não possuem dentro do processo produtivo mais do que sua força e seus instrumentos de trabalho.

14 A Luta, 3/9/1907, número 22, p. 2.

15 Cecílio Dinorá, “O Anarquismo”. In: A Luta, 2/1/1907, número 8, p. 3.

16 Cecílio Dinorá, "O que queremos". In: A Luta, 1/5/1907, número 16, p.3.

17 Em muitos pensadores anarquistas se fez presente a idéia de uma natureza social harmônica, onde a abundância seria um fator regulador natural do equilíbrio nestas sociedades (cf. Junco, 1976:43-64;341-368). No periódico A Luta, indícios desta concepção podem ser encontrados, por exemplo, em Cecílio Dinorá, "O Anarquismo". In: A Luta, 2/1/1907, número 8, p. 3. e Cecílio Dinorá, "O grande problema”. In: A Luta, 16/6/1907, número 19, p.1. 
A forma como se daria a troca da produção nesta sociedade proposta pelo grupo do A Luta levaria em consideração não a quantidade ou o valor dos produtos, mas as possibilidades e necessidades de cada grupo produtor, pois, caso contrário, acreditavam eles, alguém poderia ser lesado ou em suas necessidades ou em suas possibilidades ${ }^{18}$. Em outras palavras, o equilíbrio seria estabelecido pelas necessidades de cada grupo produtor, o que leva automaticamente a considerar as possibilidades de produção de cada um destes grupos.

Com relação às demais esferas da sociedade porto-alegrense da época, as suas críticas a ela, por este grupo do A Luta, eram bem mais radicais, pois concordantes com a proposta anárquica propriamente dita, e se dirigiam tanto ao que estava consolidado nesta sociedade, como o que se oferecia à implantação (novas práticas e normas sociais) a partir dos projetos de sociedade construídos por diferentes grupos sociais.

Questionavam, entre outras coisas, valores que impunham à mulher o "dever da maternidade", a regulamentação das uniões amorosas (no civil e no religioso) e sua indissolubilidade, e ainda o pressuposto de que a reprodução não deveria ser evitada ${ }^{19}$.

Nestas suas críticas, os anarquistas do A Luta estavam questionando valores que eram propostos por diferentes grupos desta sociedade, não se tratando, aqui, em todos os casos, de valores plenamente instituídos na mesma ${ }^{20}$. Dirigiam-se, muitas vezes, para projetos sociais que vinham concorrendo com o seu, à implantação, nesta sociedade. Dentre estes, poderia mencionar-se o pressuposto da indissolubilidade das uniões conjugais proposto pelo positivismo do PRR (cf. Leal, in: Moreira \& Hagen, 1995: 31-35).

$\mathrm{Na}$ contramão dos valores acima mencionados, os anarquistas do A Luta propunham "a união de duas pessoas para o amor" durante o tempo que estes assim entendessem e que as mulheres "procriassem

18 Cecílio Dinorá, “O Anarquismo”. In: A Luta 2/1/1907, número 8, p. 3.

19 Ver, respectivamente, Alcaime, "A greve dos ventres". In: A Luta, 17/1/1907, número 9, p. 3 e Alcaime, "A propósito do neo-malthusianismo". In: A Luta, $15 / 4 / 1907$, número 15 , p. 1

20 São bem conhecidos os trabalhos que abordam o fato das classes populares na capital terem oferecido resistência às políticas sociais que tentavam normatizar as uniōes conjugais tornado-as fixas e duradouras. Ver neste sentido: Moreira, 1993 e Arend, 1994. 
conscientemente", fazendo uso dos "tratamentos higiênicos" neomalthusianos ${ }^{21}$ para evitar uma prole indesejada ${ }^{22}$.

A crítica destes anarquistas ao estado do Rio Grande do Sul era, por sua vez, contumaz, não importando aqui, para eles, que feição o mesmo tomasse: "democrata", positivista "ou [até] mesmo socialista"23. Isso porque a sua existência representava tanto a perpetuação da "sociedade dividida em ricos e pobres, em satisfeitos e insatisfeitos", como a impossibilidade de que esta sociedade se organizasse "baseada na iniciativa individual e no livre acordo" 24.

A existência do estado nas sociedades nada mais era, segundo eles, do que uma "anomalia", já que o mesmo obrigava "a maior parte dos indivíduos a obedece[rem] leis que contrariam em absoluto suas próprias e naturais tendências e aspirações" 25 que, resumidamente, pode-se dizer, tratava-se da solidariedade que era produtora e, ao mesmo tempo, produto, da liberdade social.

Não participavam também da esfera político institucional desta sociedade pois:

"o ideal que aspira a anulação de todo o poder, porque é fonte de contínuas tiranias, não pode com razão fazer o jogo dos partidos autoritários (...). Este ideal só deve combater, por todos os meios que as circunstancias aconselham mais producentes, sempre fora da órbita governamental, contrariamente ao que seja política e autoridade." ("A Farsa Eleitoral", in: A Luta, 23/11/1907, p. 2)

21 A correlação estabelecida entre os métodos anticonceptivos propagados pelo $A$ Luta com os métodos anticonceptivos neo- malthusianos tem por base as afirmaçōes feitas por este periódico no sentido de se colocar como propagador dos métodos anticonceptivos divulgados por Paulo Robin e pela "Liga de Regeneração Humana". Ver, neste sentido, Alcaime, "A propósito do neomalthusianismo". In: A Luta, 15/4/1907, p. 1. e "A fúria do Bonzo". In: A Luta, 2/3/1907, p. 3. Tanto Paulo Robin, como a "Liga de Regeneraçăo Humana", segundo Michelle Perrot, divulgaram o neo-malthusianismo, bem como, os seus métodos anticonceptivos. Ver, Perrot, 1994, História da Vida Privada, número 4, p. 548.

22 Respectivamente, Alcaime, "A greve dos ventres". In: A Luta, 17/1/1907, número 9, p. 3.; Alcaime, "A propósito do neo- malthusianismo". In: A Luta, 15/4/1906, número 15 , p. 1.

23 "A Farsa Eleitoral". In: A Luta, 23/11/1907, número 24, p. 2.

24 "Duas Palavras". In: A Luta, 10/10/1906, número 3, p. 1.

25 Cecílio Dinorá, "O Anarquismo". In: A Luta, 15/11/1906, número 5, p. 2/3. 
Desejavam uma sociedade onde, ao abolir-se o estado, emergisse uma organização espontânea baseada no livre acordo entre todos os seus componentes.

Estes anarquistas, no entanto, apesar destas suas críticas radicais - pois negavam frontalmente e imediatamente - a estas esferas da sociedade vigente, não conseguiram sempre manter-se à margem da mesma, reproduzindo, muitas vezes, fragmentos desta sociedade. Um destes momentos teria sido quando do pronunciamento, por parte destes anarquistas, de um discurso de disciplinamento da conduta operária com relação ao uso do "álcool" (bebidas alcoólicas). Diziam que o álcool enfraquecia o corpo e o cérebro e que, portanto, não deveria ser ingerido, já que diminuiria tanto as capacidades produtivas do operário, como o potencial de sua luta contra o capital. Afirmavam, ainda, que a diminuição da produtividade dos operários trazia para eles e "as pessoas que del[es] depen[diam]", "prejuízos"26 - provavelmente a perda do emprego.

Estes anarquistas do A Luta, ao proferirem este discurso, reproduziam uma faceta da dominação do capital sobre o operariado desta cidade, visto que propunham, tal qual os burgueses, que os operários fossem produtivos, que estes se adequassem à nova ética de valorização do trabalho que se instituía na cidade (cf. Pesavento, 1989:36).

Provavelmente, um dos fatores que teria levado estes anarquistas a emitirem tal discurso encontra-se na própria influência sobre estes do "sindicalismo revolucionário". Ao quererem melhorar as condiçốes de vida dos operários, acabavam propondo - mesmo que disso não se dessem conta - que estes se adaptassem a algumas condutas desejadas nesta sociedade, a alguns valores propagados pela burguesia portoalegrense, para que não perdessem os seus empregos.

No entanto, por outro lado, ao fazerem isso acabavam não só não realizando a negação anarquista deste presente, mas contribuindo para a instauração de um outro projeto social que também buscava a sua plena concretização na sociedade porto-alegrense da época. A normalidade era, neste momento, paradoxalmente reforçada pelos que queriam a instauração de um projeto divergente daquele que, com outras finalidades, vinha tomando corpo nesta sociedade: o projeto burguês.

Cecílio Dinorá, “As 8 horas”. In: A Luta, 29/9/1906, número 2, p. 3. 


\section{Conclusão}

Como se pôde observar através desta breve exposição de alguns fragmentos do projeto de sociedade configurado pelos anarquistas do periódico A Luta, havia em Porto Alegre, nestes anos, um projeto social que se opunha aos rumos que a história vinha tomando na cidade. Mais do que isto, este projeto pretendia forjar novos rumos para a história local, pois, como se viu, produzia imaginariamente representações de uma sociedade além de "outra", também "nova".

Esta pretensão, no entanto, como também se pôde ver, nem sempre se consubstanciou em propostas totalmente radicais, tal como é desejável no anarquismo, devido ao seu conteúdo utópico. Viu-se como, em alguns momentos, este grupo de anarquistas fez concessões "temporárias" ao poder econômico que se instituía, bem como fez eco a algumas normatizações de caráter cultural difundidas por este.

Resta dizer ainda que o grupo do $A$ Luta, além de ser anarquista, era um grupo que produzia um jornal voltado para o operariado. $\mathrm{O}$ periódico A Luta era, neste sentido, um dos instrumentos utilizados por este grupo para tentar construir, na Porto Alegre dos anos de 1906 e 1907, um "sonho operário". Se tomarmos o que Baczko diz sobre a "intenção provocativa" manifesta ou subjacente às utopias (ou fragmentos utópicos) compreende-se claramente o porquê desta prática. O A Luta teria sido uma das formas encontradas, por este grupo, para fazer com que as pessoas comparassem o "real" e o "imaginário" e, por fim, desejassem a sociedade construída no avesso do presente.

\section{Referências bibliográficas}

AREND, Silvia. Um "olhar" sobre a família popular porto-alegrense (1886-1906). Porto Alegre: UFRGS, 1994 (dissertação de mestrado).

BACZKO, Bronislaw. Lumiéres de l'utopie. Paris: Payot, 1978.

BERTI, Nico. "La dimensione utopica del pensiero anarchico". In: Volontá. Rivista Anarchica Trimestrale, Milão, jun-set 1981.

BERTOLLO, Amadeo. “L'imaginaire Subversif”. In: L' imaginaire Subversif. Genebra: Ed. Noir, 1982.

HOROWITZ, Irving Louis. Los anarquistas. Madrid: Alianza Ed., 1982.

JUNCO, José Alvarez. La ideologia Politica del Anarquismo Español (1868-1910). Madrid: Siglo XXI, 1976. 
LEAL, Elisabete. Mulher e família na virada do século: o discurso d'A Federação. In: Moreira, P. \& Hang, A. (orgs.). Sobre a rua e outros lugares: Reinventando Porto Alegre. Porto Alegre: Caixa Econômica Federal, 1995.

MAITRON, Jean. Le mouvement anarchiste en France. Paris: François Maspero, 1975.

MOREIRA, Paulo. Entre o deboche e a rapina: os cenários sociais da criminalidade popular em Porto Alegre (1868-1888). Porto Alegre: UFRGS, 1993 (dissertação de mestrado).

MÜLLER, Helena Isabel. Flores aos rebeldes que falharam. Giovani Rossi e a utopia anarquista: colônia Cecília. São Paulo: USP, 1989 (tese de doutorado).

PESAVENTO, Sandra Jatahy. A burguesia gaúcha: dominação do capital e a disciplina do trabalho (RS: 1889-1930). Porto Alegre: Mercado Aberto, 1988.

. Os pobres da cidade: vida e trabalho $\mathbf{- 1 8 8 0 - 1 9 2 0}$. Porto Alegre: Ed. da UFRGS, 1994.

STOPPINO, Mario. "Autoridade". In: Bobbio, Norberto [et al.]. Dicionário de Política (vol. 1). Distrito Federal: Edunb, 1993.

VOISIN, Michel. "Sur quelques caracteristiques de l' utopie pratiquée". Recherches Sociologiques, Vol. XXI, n. 1, 1990.

WOODCOCK, George. Anarquismo: uma história das idéias e movimentos libertários. Porto Alegre: LPM, 1983. 